\title{
Catálogos de Sciencias Juridicas e Sociaes em Pernambuco, Brasil
}

Catalogs of Legal and Social Sciences in Pernambuco, Brazil

\author{
Gilda Maria Whitaker Verri \\ Universidade Federal de Pernambuco. Programa de Pós- \\ Graduação em Ciência da Informação, Brasil \\ gmverri@yahoo.com.br \\ iD https://orcid.org/0000-0001-5710-7480 \\ Karine Gomes Falcão Vilela \\ Universidade Federal de Pernambuco. Biblioteca da \\ Faculdade de Direito do Recife, Brasil \\ vilela.karine@gmail.com
}

iD https://orcid.org/0000-0002-9065-1012

\section{Resumo:}

A criação do Curso de Sciencias Juridicas e Sociaes em Olinda, Pernambuco, exigiu a formação de uma biblioteca a partir de coleções adquiridas. O trabalho tem como objetivo principal compreender e demonstrar o alcance e as características da ordenação dos livros antigos no processo de formação da coleção original do Curso Jurídico, divulgada por meio de listas manuscritas, inventários e catálogos, que se constituem e representam a própria biblioteca de época. Pelo olhar da Bibliografia histórica, da Ciência da informação e da abordagem epistemológica foi analisado o processo catalográfico de suas obras, para a constituição da biblioteca que se firmou com a compilação de seus catálogos.

Palavras-chave: Catálogos antigos, Catálogos de bibliotecas, Bibliografia histórica, Brasil.

\section{Abstract:}

he creation of the Course on Legal Sciences and Societies in Olinda, Pernambuco, required the formation of a library from acquired collections. The main objective of the work is to understand and demonstrate the scope and characteristics of the ordering of old books in the process of forming the original collection of the Legal Course, disseminated through handwritten lists, inventories and catalogs, which constitute and represent the period library itself. Through the eyes of the historical bibliography, information science and the epistemological approach, the cataloging process of his works was analyzed, for the constitution of the library that was established with the compilation of his catalogs.

KEYWORDS: Old catalogs, Library catalogs, Historical bibliography, Brasil.

\section{INTRODUÇÃo}

Desde a mais remota era cristã, quem viesse a estudar direito, e o fizesse com o apoio de um bom livro, jamais correria o risco de esquecer o que aprendera, lembrou o bibliófilo e livreiro-editor Rouveyre (2000). No Antigo Regime era tradição cultural considerar bom o que era antigo, desde que erradicado o que era ruim, muito embora nem os livros nem os homens pudessem ser considerados semelhantes. Para a bibliologia histórica, o bom livro antigo é caracterizado como um objeto composto e impresso conforme as técnicas e as singularidades dos costumes de onde foi produzido. Ou dos vínculos estabelecidos entre o idealizador do texto, mais o tipógrafo-impressor, o tipógrafo-editor, o revisor de provas, o encadernador, o mercador, o livreiro e o leitor. Ao destinatário, o leitor, importa ler, compreender ou interpretar a sonoridade e o sentido das palavras ou das imagens que integram, registram e expressam a ordem natural e 
social de conhecimentos apresentados em formatos específicos ou representados em catálogos. Operações e regras são constituídas para compilação e difusão de livros incluídos em catálogos gerados e desenvolvidos conforme o tempo e os espaços econômicos e sociopolíticos. As informações sobre onde e como esses instrumentos eram ou são produzidos, adquiridos ou identificados por marcas de propriedade ou de leitura, permitem identificar e estabelecer as vias de referência e de circulação do objeto como um todo, ou em sua relação e trajetória com os compiladores e os consulentes.

Assim sendo, o que se vai achar, perceber, interpretar ou apreciar nos catálogos de livros antigos são informações de um determinado tempo e contexto, que se expressam por meio de registros gráficos. Esses catálogos são recursos para o encontro dos objetos de leitura. No tratamento dado aos elementos representativos de cada obra estão os vestígios que demonstram o conteúdo, ou indicam em quais campos estão expostas as teorias, as práticas ou os usos do objeto referenciado. Os repertórios antigos permitem uma visão sociocultural, econômica e científica das artes do conhecimento no espaço-tempo. Estudados em separado ou em conjunto, acumulados ou organizados em listas manuscritas ou impressos, os livros antigos expõem os protocolos de descrição, as formas de controle bibliográfico e as possibilidades dos leitores de entender, interpretar, dar continuidade ou descontinuidade ao sentido da estrutura material ou do conteúdo do objeto tipográfico referenciado. As informações relativas a cada elemento representado evidenciam a materialidade do objeto impresso, o lugar social ocupado, a matriz cultural e o valor histórico do conteúdo. Ao conjunto de elementos identificados, os colecionadores chamam catálogo de livros antigos ou raros.

O livro "é um escrito (quer seja composto à tinta ou por meio de caracteres, em muitas ou em poucas páginas, o que aqui é indiferente) que apresenta um discurso que qualquer um leva ao público por meio de signos linguísticos visíveis" (Kant, 1995, p. 133, tradução nossa). Um objeto que, em palavras, imagens ou números, registra, apresenta, reproduz, suscita, assegura, põe em dúvida ou refuta informações, dados, provas, fatos, imagens, acontecimentos, pensamentos. Tal como os registros e as provas documentais para a História, ao livro se faz perguntas, aí reside sua importância histórica e, parafraseando Ricoeur (2007, p. 189) "tudo o que pode ser interrogado [...] com a ideia de onde nele encontrar uma informação sobre o passado" está escrito em livro, ou representado em catálogos. "[...]. Pode-se dizer então que a memória está arquivada, documentada” para ser recuperada, testemunhada, revelada, continuada, construída, representada, interpretada, esquecida ou anulada, que também pode demonstrar verdades, falsidades, propriedades ou impropriedades, de modo a permitir o traçado epistemológico da questão em estudo.

Então, se "os homens fizeram os livros, e os livros, por sua vez, fizeram os homens" (Chalus, 1958, conforme citado em Lebvre \& Martin, 1992, p. 10), exemplares antigos, dos séculos XV ao XIX, legitimados por privilégio régio, ou mesas censórias, relacionados em catálogos de bibliotecas, que lugar ocuparam no contexto bibliográfico de um estabelecimento para formação de juristas e de apresentação de normas jurídicas do século XIX? Por que procurar o significado dos catálogos antigos, que deram origem e suporte à biblioteca do Curso de Sciencias Juridicas e Sociaes instalado em Olinda, Pernambuco, no momento em que o avanço da virtualidade dos impressos vem se firmando e os modos de ler, pesquisar, pensar e agir em outra época diferem do espaço-tempo atual?

Exemplares antigos, como os clássicos, permitem compreender o processo de constituição do conhecimento, isto é, "são aqueles livros que chegam até nós trazendo consigo as marcas das leituras que precederam a nossa e atrás de si os traços que deixaram na cultura ou nas culturas que atravessaram (ou mais simplesmente na linguagem ou nos costumes)" (Calvino, 1993, p. 11). Relacionados, os livros de determinadas épocas, além da totalidade da composição gráfica identificadas pelo leitor, trazem marcas do contexto no qual circularam, que vão "reconstruir a maneira como os leitores produzem sentido apreendendo o texto" (Chartier, 2002, p. 251).

Alguns livros antigos podem ocupar as prateleiras dos colecionadores, mas são as bibliotecas patrimoniais que recolhem, organizam, recuperam, preservam e disponibilizam informações sobre as fontes impressas, que aproximam o leitor dos registros da memória à estrutura material oriunda dos processos e da capacidade 
técnica de impressão da época. A biblioteca por ser um lugar de recolhimento, preservação e difusão de informações, com ampla acepção, pode ser representada pela listagem dos títulos, como registrou Antoine Furetiere, o abade de Chalivoy, autor do Dictionnaire universel (1690), ao dar o exemplo do catálogo de Conrad Gesner, Bibliotheca Universalis (1545):

Biblioteca é um repositório, uma compilação de muitas obras da mesma natureza, ou de autores que foram compilados segundo o mesmo assunto. Gesner, Possevin, Photius, fizeram bibliotecas [...]. Chamamos também biblioteca aos livros que contêm os catálogos dos livros das bibliotecas (Furetiere, 1690, grifo e tradução nossa).

Assim, dar o nome "biblioteca aos livros que contêm os catálogos dos livros das bibliotecas", como explicou Furetiere e como fez o oratoriano Giuseppe Mansi, com a Bibliotheca Moralis Praedicabelis (1666-1669), também o abade de Sever, Diogo Barbosa Machado, com a Bibliotheca Lusitana editada em 1741, é saber que biblioteca, catálogo, inventário, repositório, lista, índex, tábua, bibliografia são instrumentos manuscritos ou impressos que, ao circular em diferentes tempos e contextos sociais, adotaram termos e regras tipográficas ou bibliográficas segundo diferentes objetivos ao dar acesso ao livro (Malclès, 1954) ou aos objetos, ou identificar uma presença diante da ausência. Esses instrumentos, tais como Gabriel Naudé (1876) propôs, indicam o que as bibliotecas contêm nas grandes e renomadas, nas antigas ou modernas, públicas ou particulares. Porém, os termos têm significados, se correlacionam e demonstram a arte de revelar os produtos, conforme os procedimentos teórico-metodológicos destinados a propiciar a recepção, apropriação ou circulação do sentido das informações registradas. Cada obra referenciada ou representada tem assinalado, descrido, analisado, sistematizado, classificado ou recenseado, os elementos que a compõe ou a identifica.

Os inventários e os catálogos indicam o recolhimento e sinalizam o uso de livros antigos ou raros no Curso de Sciencias Juridicas e Sociaes e estabelecem um marco para a bibliografia histórica e para a história do livro e da leitura em Pernambuco. Os elementos fixados têm função social e jurídica, visto que até princípios do século 19, para a produção e circulação de impressos vigoravam as licenças ou autorizações da Mesa do Desembargo do Paço, no Rio de Janeiro. Aqui, voltar-se para os recursos bibliográficos do passado tem por objetivo principal compreender e demonstrar o alcance e as características da ordenação dos livros antigos no processo de formação da coleção original do Curso Jurídico, divulgada por meio de listas manuscritas, inventários e catálogos que se constituem e representam a própria biblioteca de época.

Efetivar a criação do curso demandava uma biblioteca estruturada, articulada, em condições de atender professores e alunos. Mas, sem recursos para a seleção e aquisição de livros básicos, a composição do acervo teve origem com os livros antigos, inventariados, que pertenceram à biblioteca da Ordem dos padres Oratorianos de São Felipe Neri, do convento da Madre de Deus, no Recife. Os oriundos da contribuição popular, mais os enviados pela Biblioteca Nacional e Pública da Corte, no Rio de Janeiro (Veiga, 1981) completaram o acervo inicial. Portanto, é pressuposto que os catálogos dos livros recebidos pelo antigo Curso de Sciencias Juridicas e Sociaes propiciaram e demarcaram a cultura bibliográfica da denominada Biblioteca da Faculdade de Direito até os dias atuais.

Situar a origem da Biblioteca é contextualizar suas raízes no terreno destinado à implantação do Curso, é compulsar as listas manuscritas dos livros dos Oratorianos, os catálogos dos responsáveis pela organização e cuidado com os livros, os estudos históricos de Bevilaqua (2012) e de Veiga (1981), as memórias de Phaelante da Câmara e de outros professores, os relatórios anuais dos Ministros apresentados à Assembleia Geral Legislativa, bem como analisar as recentes pesquisas documentais de Rodrigues (2017) e de Vilela (2020) efetuadas nos arquivos da Faculdade de Direito do Recife. As imagens do passado, pelo olhar da bibliografia histórica, da ciência da informação e da abordagem epistemológica dão a visão do processo catalográfico das obras destinadas à constituição da biblioteca, que se firmou ao selecionar e revelar o acervo em momento político conturbado.

As listas e os catálogos dos livros antigos preservados na Faculdade de Direito da Universidade Federal de Pernambuco trazem informações que levam às pistas e às indicaçóes das obras que formaram o acervo 
original. Livros preservados trazem à tona as leituras do passado, em que conteúdo, encadernação, guardas, miolos e marcas, suscitam histórias de uso, tendências de leitura e anotações feitas. Vestígios contextualizados permitem entender que processos técnicos e cognitivos dão sentido às questões presentes de forma e de significado aos livros antigos. O percurso à letra da cultura bibliográfica passa pela via do espaço-tempo sociopolítico dos catálogos.

\section{A formação da biblioteca do Curso de Sciencias Juridicas e Sociaes em Olinda}

Em um país onde livros eram objetos de raro afeto havia mais de três séculos, os livros existentes sempre estiveram mais próximos de ordens religiosas. E distantes se mantiveram até quando foi instituído um espaço para leitura e estudo destinado ao público acadêmico. Isso quando em agosto de 1827, o Brasil Império viu surgir a criação dos primeiros Cursos de Sciencias Juridicas e Sociaes: um em Olinda e outro em São Paulo. Esses locais estratégicos deveriam formar "futuro Magistrados hábeis e inteligentes, sendo aliás de maior urgência acautelar a notória falta de Bacharéis formados para os lugares da Magistratura pelo estado de independência política" (Brasil, 1827), para extensão e supervisão do poder central nas Províncias.

A lei de 11 de agosto de 1827 (Brasil, 1827) promulgada por D. Pedro I, regulamentada pelos Estatutos do Visconde de Cachoeira, que buscava firmar-se a partir dos Estatutos de Coimbra, valeu até o decreto de 7 de novembro de 1931. Os Estatutos não previram a organização de livros para uma biblioteca, mas que aos lentes caberia fazer a escolha de textos ou, não existindo os já feitos, compêndios seriam elaborados de acordo com as doutrinas do sistema jurado pela nação. Os manuais elaborados, depois de aprovados pela Congregação e Assembleia Geral, o governo os faria imprimir e repassar aos autores o privilégio da obra por dez anos. Dos alunos era exigido o conhecimento de língua francesa, gramática latina, inglês, retórica, filosofia racional e moral, geometria, geografia. - Para candidatos, o Curso preparatório passou a ser ministrado no Colégio das Artes a partir de 1832.

Longas e divergentes discussões ideológicas sobre as cadeiras a ministrar e os compêndios a indicar faziam parte das assembleias dos lentes. "Precisava-se, todavia, distinguir os livros de texto oficiais, os compêndios, dos livros de texto de fato, circulando em Olinda” (Veiga, 1981, p. 69), visto que as referências básicas para o curso estavam nos estatutos redigidos pelo então Deputado Luís José de Carvalho e Melo, o Visconde de Cachoeira, em 1825. As matérias indicadas para o primeiro ano eram: Direito Natural, Público, Análise de Constituição do Império, Direito das Gentes [i.e., natural] e Diplomacia, para isso, deveriam dispor de livros sobre Direito Romano, princípios do Direito Civil, Ordenações do Reino, princípios políticos de Benjamin Constant, Jeremy Bentham, inclusive os manuais elaborados por professores (Câmara, 1904).

Entraves como falta de recursos e de textos fizeram o diretor interino, Lourenço José Ribeiro, tentar prover as disciplinas com um acervo especializado, por meio de doações de livros. Por isso, o recebimento dos livros da Ordem dos padres Oratorianos de São Felipe Neri, composto de muitos sermonários em latim, os quais talvez tenham servido à disciplina Direito Público Eclesiástico. Da coleção, foi feita a Rellação dos livros que em virtude da lei, que, extinguiu [a] Congregação de S. Felipe Néri, se mandou, pela Junta da Fazenda desta Província entregar, para a Biblioteca do Curso Juridico d'Olinda, ao Director Lourenço José Ribeiro [1831].

Assuntos alheios ao direito e outros foram ofertados às primeiras turmas de bacharéis, como a doação pessoal do aluno Felipe Lopes Neto Júnior, Syntagma Secundum Ordinem Institutionum Justiniani, escrito por Johann Gottlieb Heineccius, referência para o Direito Natural, no primeiro e, no segundo ano, para o direito das Gentes (Rodrigues, 2017). Porém, a indisponibilidade de títulos e de aquisição destinadas às nove cadeiras do currículo suscitavam reclamaçóes de todo tipo entre alunos e professores, que continuavam a listar pedidos de compras de obras atualizadas para as disciplinas do terceiro ano em diante: Direito Pátrio Civil; Direito Pátrio Criminal com a teoria do processo criminal; Direito Mercantil e Marítimo; Economia Política; Teoria e prática do processo adaptado às leis do Império. 
Os livros foram instalados no Mosteiro de São Francisco, Olinda, local "cercado de matos", de difícil acesso, distante do Curso e dos alunos. Em um salão ficavam as estantes e os livros que deveriam atender o currículo. Além dos trâmites administrativos, "a organização de bibliotecas estava sujeita a limitações financeiras e arquitetônicas” lembrou Burke (2003, p. 86). A organização ficou a cargo do antigo participante da Revolução de 1817, em Pernambuco, Bazilio Quaresma Torreão, que obteve uma subscrição voluntária junto aos comerciantes para aquisição de livros. As publicações compuseram a Lista das Pessoas, que tem dado obras para a Biblioteca Pública de Olinda, que estão a cargo do abaixo assignado (Rodrigues, 2017).

Em 1832 também foram ofertados 2.269 exemplares elencados no Catálogo dos Livros da Bibliotheca Nacional e Pública da Corte - que por ordem da Secretaria d'Estado dos Negocios do Imperio forão remethidos - à Provincia de Pernambuco 1832, datado e assinado, em 25 de Junho de 1832 pelo Ajudante Bibliothecario Conego Felisberto António Pereira Delgado. Com títulos inadequados ao currículo, as obras foram referenciadas em colunas: autor, título, local de impressão, ano e quantidade de exemplares, classificadas por categorias: Belas Letras, Ciências e Artes, Teologia, Direito, História.

Diante das desiguais e precárias coleções, a composição inicial do acervo não correspondeu às reais necessidades programáticas do curso. Seria por isso que Bazilio Quaresma Torreão (1831-1833), enquanto responsável pelo recebimento dos exemplares, não tenha tido o cuidado de organizar o material? Ou por que era pressuposto os catálogos somente disseminarem livros conforme o sistema jurado pela nação? Ou seria por causa das circunstâncias em que ideias e movimentos políticos entre conservadores e liberais provocavam choques na sociedade e alteravam, de certa forma, os debates e as ações de ordem acadêmica, que repercutiam em conflitos nas congregações e na indisciplina estudantil? Ou por causa da repercussão na cidade, da crescente circulação de ideias em livros de autores franceses e de alguns alemães, que tratavam de problemas políticos, sociais e de direito público eclesiástico? - Respostas ainda sem clareza.

Todavia, ocorreu que em Olinda e no Recife a partir de 1825 aumentara o número de tipografias e a impressão de jornais com diferentes matizes políticos, com visões partidárias antagônicas. Atraiam o crescente interesse dos leitores os seguintes jornais: Diário de Pernambuco, Argos Olindense, O Clarim Literário, Jornal do Recife, A Província, Jornal Pequeno, O Carapuceiro, Guarda Nacional, Diario Novo, Estandarte Católico, Revista de Instrução Pública, mais: O Progresso, Revista Acadêmica. A comunicação, os movimentos e os debates de ideias entre alunos, professores, políticos e comerciantes repercutiram em várias ações de insurgência, motins ou levantes, quase sempre com participação de alunos do Curso Jurídico. Foram assim: a Setembrizada (1831), pró D. Pedro I, recém abdicado; a Novembrada (1831), de cunho nacionalista; a Abrilada (1832), movimento dos grandes comerciantes com o apoio dos estudantes, em vista da Independência. — Ainda que, mais tarde, fosse registrado: "nos autos do inquérito da Revolução Praieira [1848-1850], não comparece um único estudante de Direito para depor, quer como indiciado, quer como testemunha" (Veiga,1982, p. 27). Entretanto, foi marcante a presença do líder liberal, professor Jerônimo Vilela Tavares, redator dos jornais Guarda Nacional e Diário Novo, autor do Compêndio de Direito Público Eclesiástico, deportado para Fernando de Noronha.

\section{A BIBLIOTECA EM INVENTÁRIOS}

Tantas eram as dificuldades e os conflitos entre professores e alunos que, para reduzir a indisciplina, a Regência, em nome do Imperador D. Pedro II, houve por bem sancionar os novos estatutos, provisoriamente aprovados, para servir de Regulamento aos cursos, conforme o decreto Imperial de 7 de novembro de 1831 (Brasil, 1831). Assim, foram normalizados: exames preparatórios, matérias exigidas, taxas, controle de horas e didática das aulas, defesas para obtenção do grau de bacharel, férias, ingresso de professores, bem como critérios de escolha dos compêndios. De certo modo, era perceptível que havia livros na cidade, mas que inexistiam para o aprendizado específico. O capítulo 16 do Regulamento expos: .Haverá huma bibliotheca que será composta, não só de obras sobre sciencias juridicas e sociaes, como sobre aquellas que 
são hoje geralmente reconhecidas como indispensáveis para o verdadeiro conhecimento e adiantamento dellas" (Brasil, 1931). Porém, cabia à Congregação a designação das obras, mediante submissão ao Ministro do Império, para efetivar as compras. Ainda, "Hum bibliothecário será encarregado, debaixo da inspecção do Director, do bom arranjo, classificação, e conservação das obras, e da polícia, no recinto da Bibliotheca, mantendo o silencio necessario, para não serem perturbados os que nella se quizerem instruir" (Brasil, 1931).

Essas determinações levaram Umbelino Ferreira Catão (1833-1839), bacharel em Direito, a ser o responsável por organizar os livros. Ao chegar, oficializou ao Ministro António Pinto Chichorro da Gama que "não achou nem um cathalogo geral das obras como também achasse todos os livros sem nenhuma classificação e de alguma maneira abandonados" (Diário de Pernambuco, 1833, conforme citado em Rodrigues, 2017, p. 78). A declaração refletia o entendimento sobre a função, o alcance e as possibilidades de uso que um inventário ou um catálogo conferiam à biblioteca, por meio dos protocolos de descrição, para demonstrar o quadro geral das obras existentes e faltantes. A inexistência do repositório também era sentida pela Direção do Curso, como visto em ofício:

Pedindo eu ao encarregado da Bibliotheca a lista dos livros que ali se acha, informou-me elle verbalmente, o que exigi por escrito, haverem já classificado, e inscritos no cathalogo mil e setenta volumes já promptos, mas ainda não inscriptos, tresentos e cincoenta calculando em mil os que ainda estão por arranjar; sendo de Direito a menor porção a neste ramo a mayor parte delles de Direito Canonico. (Rodrigues, 2017, p. 105).

A Direção reconhecia ser imprescindível a compilação do catálogo, para dar aos leitores a garantia de poder localizar, compulsar e validar os autores, com rapidez, vez que a "sala do convento de $S$. Francisco, acanhada, quente e quase fora da cidade, tira toda a ocasião de ser frequentada, o que a torna, além de dispendiosa, quase totalmente inútil" (Faculdade de Direito do Recife, 1835) ou como escreveu o visconde de Goiana: "A chamada biblioteca não é outra coisa mais do que uma pobre estante de livros de jurisprudência, enchendose outras estantes da sala com livros eclesiásticos que foram de diferentes congregações" (Bevilaqua, 2012, p. 647). - O local e os livros eram inadequados para os estudos propostos.

A validação das obras era definida a partir de um inventário ou como Eco (2010) chamaria, uma lista prática, referencial, que demonstrasse autores e títulos como se fossem objetos ou mercadorias expostas em estantes. Desse modo, o primeiro inventário ou livro de tombo fora aberto pelo diretor do Curso à época, o bispo Thomas Noronha: Inventario dos livros, que se achão na Bibliotheca da Academia Juridica de Olinda, sita no Convento de S. Francisco, e de que o Bibliothecario he obrigado a cuidar e dar conta. Tem 206 folhas; as quaes todas numerei e rubriquei.

O caminho estava dado para a elaboração do Inventario da Bibliotheca Publica e Curso Juridico de Olinda feito por Umbelino Ferreira Catão [Inventario da Bibliotheca Publ [...] Curso Juridico de [Olin] da feito por

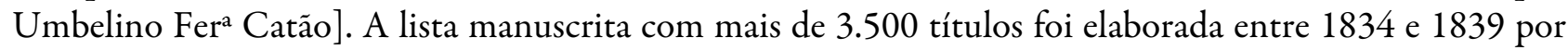
Catão, de forma simples, sem ordem alfabética, com informações correspondentes às estantes. O manuscrito, em papel de má qualidade, escrito à tinta ferrogálica em três colunas, tinha na primeira, a sequência numérica, na segunda, sem ordenação alfabética, o sobrenome do autor, e o título abreviado em latim, na terceira, os quantitativos dos exemplares. Na lista, sem notas tipográficas nem origem da aquisição, constavam as obras confiscadas da Ordem dos Padres Oratorianos, quando de sua extinção em 9 de dezembro de 1830.

Para o responsável pelos registros, não foram as ideias contidas nas obras o que precisava ser inventariado, mas os autores e os títulos listados de forma abreviada, seguidos do total de volumes. Os livros elencados não corresponderam aos 4.422 exemplares, os quais deveriam somar os três conjuntos documentais recebidos: 1.689 volumes dos padres Oratorianos, 264 volumes de doações particulares e 2.269 volumes provenientes da Biblioteca Nacional. Desses, quais os exemplares qualificados para as matérias curriculares? Não se sabia. A seleção dos livros exigia mais de uma pessoa e em não havendo, o resultado foi a falta de resumo ou descrição indicativa da obra.

Como diria Farge (1986), as listas nasceram da desordem, visto que as informações colhidas eram fragmentadas, apenas indicativas, abreviadas, sem as notas tipográficas referentes ao período de 1833 a 1839. 
Nas estantes, as prateleiras reuniam um ou mais assuntos, conforme as marcas deixadas nas folhas de guarda iniciais dos livros antigos. Embora as listas apenas comunicassem ou registrassem os autores arrolados fora de ordem alfabética, os elementos fundantes demonstraram a totalidade da coleção. - Vale lembrar, que a ordem alfabética era conhecida desde o século 11 pelos eruditos bizantinos, embora tardiamente divulgada ou utilizada pelos europeus. Assim, firmado sem ordenação, o inventário elaborado por Catão mostrou a falta de divisão por áreas, temas, assuntos, ou origem da doação, contudo, dava a conhecer as pistas ou vestígios do universo autoral levado a termo por proprietários anteriores. Nesse sentido, as informações que eram apenas uma memória livresca, formaram os primeiros dados ou matéria prima para representar a biblioteca no inventário correspondente. De certa forma, o levantamento espelhava a situação cultural e o despreparo dos responsáveis para as funções técnico-administrativas específicas, e a falta de pessoal para auxiliar na organização geral.

A composição do inventário deu maior visibilidade à diversidade de títulos, ao identificar os escritos em latim como predominantes na biblioteca. Entre os autores arrolados por Catão, Bevilaqua (2012) assinalou os mais difundidos entre os intelectuais: Aristóteles, Homero, Hipócrates, Newton, Bossuet, Malebranche, Montesquieu, Bentham, os portugueses Silvestre Pinheiro, Melo Freire, Manuel Bernardes, mais as seletas latinas. Sobre os livros, Veiga $(1981,1982)$ menciona os autores referenciados adotados pelos professores, que promoveram a leitura como meio de comunicação de ideias. Em O Carapuceiro, o padre Lopes Gama (1983) divulgou autores apresentados em aulas, como: Beccaria, Roussy, Saint-Simon.

O trabalho realizado por Catão (1839) incluiu o registro de periódicos que serviam de elo entre a Europa e o local, ao divulgar ideias e outros conhecimentos. Alguns títulos lidos e citados por Frei Caneca, como a Revue Encyclopédique constavam do levantamento. Acrescentados também à lista: Revue Britannique, Edinburg Review, Revue des Deux Mondes, Journal de l'Institut Historique, Jornal des Connaissances Utiles, Journal des Economistes. Impressos em que valores ou desvalores diferiam dos compêndios produzidos e aprovados pela Congregação e pela Assembleia Geral.

Em defesa do regime, apenas os textos oficiais valiam para as aulas e os exames finais. Mas traduções, como Lições de Direito público constitucional, de Ramon Salas, publicado em Olinda em 1832 também faziam parte das referências estudadas, assim como o compêndio de Zeiller, Direito natural, traduzido de forma clara, por Pedro Autran. - Títulos novos, em versão feita por alunos, eram dados ao prelo e anunciados pelo Diário de Pernambuco, para incentivar leitores e o movimento editorial em Olinda e, no Recife onde várias lojas de ferragens e miudezas vendiam livros de filosofia, direito, história, ciências, gramática, dicionários, assuntos diversos. Para avaliar os livros, a livraria do Arco da Conceição, na ponte do Recife, teve em 1838 um catálogo divulgado no Calendário civil da Província (Veiga, 1981).

\section{A Biblioteca em catálogos}

Desde quando esteve na direção do Curso Jurídico (1835), o padre Miguel Lopes Gama advogava a transferência de Olinda para o Recife, onde a espacialidade e a vasta população talvez reduzissem os aquartelamentos e os movimentos estudantis, o convívio de mestres com alunos, a insegurança na cidade e a travessia do istmo, como ocorria. Porém, só em 30 de março de 1853 o decreto N. 1.134 mudou a denominação de Curso Jurídico para Faculdade de Direito e permitiu a transferência de local, o que se efetivou em 1854, com a denominação alterada pelo decreto n. 1.386, de 28 de abril (Brasil, 1854), no artigo $1^{\circ}$ Os actuaes Cursos Juridicos serão constituídos em Faculdades de Direito; designando-se cada huma pelo nome da Cidade, em que tem, ou possa ter assento. Quanto à biblioteca, os artigos 140, 141 e 142 especificavam:

Em cada Faculdade haverá huma Bibliotheca destinada especialmente para o uso dos Lentes, e dos alumnos, mas que será franqueada a todas as pessoas, que alli se apresentarem decentemente vestidas. Será formada com preferencia de livros proprios das sciencias que se ensinarem na Faculdade. [...]. A Bibliotheca estará a cargo de hum Bibliothecario, que terá hum 
Ajudante. [...]. O Ajudante será encarregado da escripturação da Bibliotheca, e do trabalho interno da mesma [...] (Brasil, 1854).

O acervo foi para o Convento de N. Sra. do Carmo, no centro do Recife, próxima ao Pátio do Colégio [dos Jesuítas] onde o Curso passou a funcionar com novas aquisições, e a inserção dos livros do professor Tobias Barreto (1890). Pela primeira vez, desde a criação, a Biblioteca estava próxima dos lentes e dos alunos, com aquisições para novas disciplinas e a aplicação dos princípios de organização.

Entre 1854 e 1875 foi bibliotecário o monsenhor Joaquim Pinto de Campos nascido em Flores, PE, professor também do Colégio das Artes. Monsenhor pela igreja romana, membro de várias academias de ciências fora do Brasil, autor de artigos de jornais, sermões, orações fúnebres, discursos — posteriormente primeiro biógrafo de D. Pedro II (Blake, 1898) e do Duque de Caxias - eram as credenciais de sua biografia. Para a elaboração do Catalogo da Bibliotheca da Faculdade de Direito do Recife de autoria de Campos (1860), na Typographia Commercial de Geraldo Henrique de Mira \& C., 1. andar, Recife, as obras foram ordenadas por classes ou assuntos, como a Philosophie de Kant. Mas é preciso lembrar que, no ano anterior, o Imperador D. Pedro II, fizera questão de conhecer a Biblioteca, por ser grande leitor, inteirado das últimas publicações sobre artes e ciências editadas fora do Brasil. Assim, registrou em seu diário:

\footnotetext{
Tem bons livros novos, porém muito pouco próprios dum curso de direito e das matérias preparatórias e bastantes alfarrábios de teologia talvez vindos dalgum convento. Há catalogo que se está acabando de imprimir; mas não vejo classificação dos livros nem indicações dos lugares para acha-los; o cônego Pinto Campos, que é o bibliotecário, disse que não era difícil acha-los por serem poucos; contudo o número não é muito diminuto (Diário de Pernambuco, 1833, conforme citado em Rodrigues, 2017, p. 107).
}

A biblioteca vista pelo imperador refletia de forma negativa a ausência de cultura bibliotecária que marcava, pela falta de ordem, tanto classificatória quanto catalográfica, o acervo de um estabelecimento de ensino superior. As práticas revelaram que os responsáveis pela disponibilização das obras poderiam ter articulado sistemas de gestão, visto serem pessoas formadas, com posições políticas definidas, portadores de bagagem intelectual diferenciada, que conviviam com lentes autores e tradutores de textos de repercussão local e nacional. Assim, o monsenhor Campos tirou das estantes as novas aquisições para, com gesto bibliográfico, somente dar às obras recém adquiridas uma ordenação alfabética, condizente com dez classes de assuntos: 1 Direito Natural, Publico, das Gentes, Constitucional; 2 Direito Ecclesiastico, Theologia Moral e dogmática, Historia Sagrada e Religião; 3 Direito e Legislação criminal, medicina legal e systema penitenciario. 4 Direito Romano, Direito Civil francez e patrio. Practica do processo civil e criminal. Praxe do foro e Legislação; 5 Direito e Legislação comercial; 6 Economia politica; 7 Direito Administrativo; 8 Philosophia; 9. Geographia e, Historia; 10 Clássicos Portugueses, Diccionarios e encyclopedias.

$\mathrm{Na}$ verdade, o catálogo publicado em 1860 mostrava, sem detalhar, a localização física dos livros, a ordem alfabética do sobrenome dos autores, conforme a classificação de assuntos, títulos às vezes abreviados, quantidade, indicação da tipologia, ou seja, livros ou periódicos, sem notas tipográficas. Portanto, o catálogo era apenas uma parte da representação da biblioteca, com alcance limitado, propondo demarcar a mediação entre o leitor e a obra. Esse recurso bibliográfico, de caráter sequencial, que não trazia o conteúdo referente aos itens destacados, teve como propósito cumprir o decreto 1.568 de 24 fevereiro de 1855 (Brasil, 1855), promulgado pelo imperador, o regulamento complementar dos estatutos das Faculdades de Direito do Império. Com as estantes em desordem, a organização numérica dos livros foi imposta por ato superior, em ação centralizada.

Por decreto Imperial, catálogos sucessivos deveriam ser produzidos de quatro em quatro anos. Essa iniciativa de relacionar o acervo parece não ter partido de Pernambuco. Enquanto bibliotecários, os professores davam pouco destaque à organização bibliográfica como meio facilitador de leituras. Os autores das memórias históricas anuais do Curso, escritas por professores, por vezes mencionavam a existência da Biblioteca, de seus serviços ou dos lentes que passavam por lá. Assim, Araújo (1880) cita o cônego Francisco Rochael Pereira de Brito Medeiros e o jurista Olímpio Marques da Silva (1875-1878). Seguidos de Affonso 
de Albuquerque e Beviláqua, que compilara um catálogo enquanto responsável pelo acervo (1884-1889). — Documento esse até o presente não localizado.

Após Clóvis Beviláqua, o cargo foi ocupado por Manoel Cícero Peregrino da Silva, nomeado em julho de 1889, ano marcado pela Proclamação da República. Mas logo foi substituído pelo professor e escritor Joaquim Carneiro Vilella, fundador da Academia Pernambucana de Letras. Contratado como lente substituto também sócio honorário do Instituto Archeologico Geographico Pernambucano e membro do Tribunal do Júri, Peregrino retomou as atividades e dedicou-se à organização bibliográfica, para fazer da Biblioteca o "lugar das conexões", conforme expressão de Damien, citado por Melot (2006).

\section{AS ORDENS REPUBLICANAS}

Do período regencial até o Segundo Império, os muitos conflitos entre liberais e conservadores e as circunstâncias políticas ocorridas no país provocaram diferentes feitos: abdicação de D. Pedro I; proibição do tráfico negreiro (1831); reforma da Constituição (1834); rompimento (1863) e reatamento (1865) diplomático entre Brasil e Inglaterra, guerra com o Paraguai (1864); Tratado da Tríplice Aliança (1865); subvenção para a imigração (1871); interligação telegráfica por cabos submarinos, entre Pernambuco e a corte (1873) e, ano seguinte, com Portugal; instalação de companhia telefônica (1880); manifestações a favor do fim da escravatura.

A ebulição política em 1889 levou à proclamação da República, seguida em 1891 da promulgação da Constituição Estados Unidos do Brasil. Atos que levaram o marechal Deodoro da Fonseca à presidência, seguido de renúncia a favor do vice Floriano Peixoto. Ao ser instalada a República, o Governador de Pernambuco, Sigismundo Gonçalves foi deposto e substituído pelo capitão Alexandre José Barbosa Lima, em um tempo marcado por golpes, quarteladas, fuzilamentos e intensa movimentação de políticos e estudantes.

$\mathrm{Na}$ pasta da educação, ainda em 1891 o curso jurídico foi separado do social. Novos atos e decretos redirecionaram os estudos superiores, lideranças, disciplinas. As ordens para os livros, uso e manuseio, vieram pelo alto, ou seja, por sentenças da administração central. Para os Cursos Jurídicos e para a Faculdade de Medicina, do gabinete da Presidência da República, do militar Floriano Peixoto, e ministro Fernando Lobo, emergiu o decreto $\mathrm{n}^{\circ} 1.159$, de 3 de dezembro de 1892, que Aprova o Código das disposições comuns ás instituições de ensino superior dependentes do Ministério da Justiça e Negócios Interiores. A Educação estava subordinada a esse Ministério, e o dispositivo, no capítulo 7, Da Bibliotheca tratava de fazer chegar à administração, por unidade institucional, o controle das consultas aos livros, cabendo ao bibliotecário "apresentar mensalmente ao diretor um mapa dos leitores da biblioteca, das obras [...]; outrossim uma relação das obras, que mensalmente entrarem para a biblioteca, acompanhada de notícia, embora perfunctoria, da doutrina de cada uma delas" (Brasil, 1892). Era um modo que permitiria, por meio das listas, de catálogos e de consultas, traçar as tendências político-ideológicas dos documentos adquiridos ou em circulação nos cursos superiores. Ao mesmo tempo, o Código regulamentava o acesso aos impressos, exigia procedimentos técnicos de organização e controle das consultas. Dessa forma, cabia ao Estado determinar as obrigações e supervisionar o bibliotecário em suas atividades.

O artigo 145 do decreto impôs: Haverá uma biblioteca em cada estabelecimento destinada a lentes e alunos, mas que será franqueada a todas as pessoas decentes que ali se apresentarem". [...] A biblioteca será de preferência formada de livros, mapas, memórias, impressos ou manuscritos [...] (Brasil, 1892). Assim, estava em destaque a importância de ter método para organizar e classificar os formatos impressos para "em um piscar de olhos", a tudo identificar, o que lembrava a recomendação escrita no século 17 por Naudé sobre a importância da tipologia documental. Por prioridade do decreto: "Haverá na biblioteca quatro catálogos: a) das obras, pelas especialidades de que tratarem; b) das obras, pelos nomes de seus autores; c) dos dicionários; d) das publicações periódicas". O catalogo de autores seria organizado pelo primeiro nome, ou pelo mais conhecido, para que "se achem inscritas todas as suas obras existentes na biblioteca" (Brasil, 1892). 
A estratégia para uso desses instrumentos fazia dos catálogos classificados o meio essencial para inventariar a documentação, servir de guia para identificar, avaliar e comparar autores e assuntos, acelerar o tempo de localização do objeto e motivar os alunos. Além de incentivar a capacidade intelectual do leitor e firmar a competência social da biblioteca, mesmo que os documentos não pudessem ser compulsados. $\mathrm{O}$ modo de dispor as informações nos catálogos permitia visualizar a arquitetura ou a estrutura documental dos campos de consulta. Essa base informacional assegurava os instrumentos para supervisão e controle políticoideológico sobre o acervo.

Dar aos catálogos a função de matriz histórica, refletia a imagem de cada obra referenciada e evitava que os leitores fossem percorrer as "tantas estantes competentemente numeradas quantas forem necessárias para a boa guarda e conservação dos livros, folhetos, impressos e manuscritos" (Brasil, 1892). Era preciso também que, organizados os catálogos, os livros fossem colocados nas estantes por ordem numérica. Isso sem esquecer: "o catalogo dos dicionários compreenderá todos os glossários, vocabulários e enciclopédias, distinção das especialidades; ainda que estejam incluídos em outros catálogos" (Brasil, 1892). Mais: "no catalogo das publicações periódicas se mencionarão as revistas, teses, bibliografias, memorias, relatórios e quaisquer impressos que tenham o caráter de periódicos" (Brasil, 1892).

Marcados pela coerção sobre a cultura das humanidades e científicas na sociedade colonial, os dispositivos burocráticos da República continuaram a centralizar as regras para a leitura e as relações entre saber e poder, como determinaram os dois artigos: "Em hipótese alguma sairão da biblioteca livros, folhetos, impressos ou manuscritos" (Brasil, 1892). [...]. Nos salóes de leitura, sob a vigilância de um guarda, os catálogos podiam ser consultados. - Paradoxalmente, a consulta e a leitura seletivas, regradas pela administração pública, reduziram o número de obras manuseadas e tornaram possível a preservação dos livros antigos. - O decreto definia quem e como seria a formação e o controle sobre o usuário: "Na biblioteca propriamente dita só é facultado o ingresso aos membros do corpo docente e seus auxiliares e aos empregados da Faculdade; para os estudantes e pessoas que queiram consultar obras haverá uma sala contigua" [...] (Brasil, 1892).

$\mathrm{Na}$ República, sem a aparente interveniência técnica de responsáveis pelas práticas documentais, a forma de restringir o acesso ou a circulação das coleções, vinha na contramão de Naudé (1876), que preconizara a abertura das bibliotecas para aprofundar a aprendizagem e multiplicar conhecimentos. - É verdade que, no século 18, o controle bibliográfico da Coroa portuguesa deixara marcas político-ideológicas muito negativas. - Assim, os textos administrativos do governo central determinaram o modo de gestão da informação e das práticas intelectuais executadas pelo bibliotecário. E definiram os catálogos especificados no Regulamento, com indicações e informações concentradas ou dispersas sobre as obras recolhidas, identificadas, classificadas, de forma a permitir comparar, avaliar, relacionar, as referências ou controlar o fluxo e as tendências do conhecimento registrado. Conhecer os sistemas de organização que estavam em uso nas bibliotecas europeias era missão dada aos professores que viajavam em busca de estudos atualizados. O bibliotecário deveria selecionar e propor ao diretor a compra de bons livros, assinaturas de jornais e periódicos para a complementação das coleções, controlar o mapa de leitores e de temporalidade das obras consultadas e das adquiridas, sempre acompanhadas de notícias sobre a doutrina de cada uma. Portanto, perante o poder central, a biblioteca era um local de convergência e divulgação de informações com função sociopolítica e cultural sob o controle da instância superior, nos limites administrativos e orçamentários. De forma complementar, por meio da marca de propriedade do material bibliográfico, os catálogos permitiam e indicavam a localização geográfica e o mapeamento de cada documento existente por localidade.

\section{Catálogo em destaque}

Ao retomar as atividades, Cícero Peregrino, que fazia crescer o número de bons livros e revistas, pensara em produzir um catálogo para assegurar "uma melhor formação de todos os estudiosos de qualquer arte e ciência” (Gesner conforme citado em Araújo, 2018, p. 74). Portanto, não era apenas cumprir a determinação 
do Código das disposições comuns às instituições de ensino superior. Era uma forma de gerir o conhecimento, de identificar a autoridade e a idade do documento, de localizar as oficinas tipográficas, de permitir a avaliação e a comparação entre referências. De demonstrar a importância dos livros para as humanidades e as ciências.

Assim, os livros deveriam estar encadernados, como exigia o decreto no 1.159 de 1892 (Brasil, 1892), e o catálogo organizado de modo sistemático e alfabético, a fim de "encontrar de preferência obras referentes a determinado ramo dos conhecimentos humanos. [...] Adotar também um plano especial, subordinado à natureza da biblioteca e a multiplicidade dos assuntos sobre que versam as obras catalogadas", conforme Advertencia assinada no Catalogo Geral da Faculdade de Direito do Recife (1896). Considerado um trabalho fundante, que teve repercussão no meio acadêmico pela forma inovadora de apresentar os livros, o catálogo trazia o plano geral no final do livro e envolvia o seguinte: Indice, a primeira parte foi dedicada ao Catalogo Systematico em que as matérias estão divididas em quatro tipos: Catalogo das obras pelas especialidades de que tratam, com exclusão de diccionarios e publicações periódicas; Catálogo do Diccionarios - Comprehendendo todos os glossários, vocabulários e encyclopedias; Catalogo das Publicações Periódicas - Comprehendendo revistas, theses, bibliografias, memorias, relatorios e quaisquer impressos que tenham o caracter de periódicos; Catalogo Alphabetico, com as obras em ordem alfabética de autoria, pessoa física ou institucional. $\mathrm{Na}$ segunda parte do Índice, as matérias não estavam mapeadas por estantes, mas foram divididas em duas seções, a primeira, Sciencias jurídicas e sociaes onde constavam 20 assuntos, p. ex: Philosophia do Direito; Direito romano [...]. A segunda seção foi para as Sciencias physicas e naturaes, divididas em 17 classes de assuntos, como: Sciencias medicas, Mathematica, Religião [...] e Variedades.

Todavia, as informações básicas prestadas na Advertencia não foram suficientes para explicar ao leitor qual método bibliográfico foi usado para estruturar ou seguir os critérios recomendados pelo código, e disponibilizar o catálogo geral, sistemático e alfabético, o que deixava dúvidas quanto à origem e aplicação das normas técnicas. O trabalho registrou 2.200 títulos, distribuídos em 6.717 volumes de livros, obras de referência e publicações periódicas, embora todo esse material, enquanto indicação bibliográfica, pudesse ser considerado uma abstração, segundo Melot (2006), visto que a obra só estava disponível nas estantes. Porém, a ordem para referenciar os livros, merece destaque: "Um catálogo de assuntos classificados [...] emprega códigos numéricos ou alfanuméricos - sistemas de classificação - para representar os assuntos" (Mey, 1995, p. 72, conforme citado em Vilela, 2020, p. 98). Portanto, mesmo sem usar os códigos numéricos para representar os assuntos dos livros, o catálogo foi considerado "sistemático por apresentar o acervo distribuído em classes e suas subdivisões" (Vilela, 2020, p. 98). Peregrino deu à questão autoral destaque em negrito, para identificar, localizar e correlacionar textos produzidos por uma mesma pessoa ou instituição. Para referenciar as obras, recorreu a folha de rosto, mencionando a falta quando necessário. Fez uso de remissivas, sem mencionar o número de tombamento. Com acréscimos e ajustes, os dispositivos do Código expostos por decreto repetiam as instruções decretadas anteriormente, mas adaptadas por Manoel Cícero Peregrino da Silva.

O catálogo foi o instrumento de consulta que deu certo para grande número de pessoas, porém, era preciso que fosse demonstrado o fluxo de novas aquisições de mérito científico, por meio de listas semestrais, em aditamento ao impresso, pleiteou Lacerda (1894), lente de filosofia e história do direito, ao elogiar o desempenho e a dedicação demonstrados por Peregrino. Em defesa do crescimento do acervo, o autor do texto acrescentou o posicionamento do bibliotecário enviado ao diretor:

Um meio de crear outros recursos para a Bibliotheca seria adoptar um imposto especial para ellla, pago por cada alunno no acto da inscripção; imposto usado em diversos estabelecimentos de Instrucção Superior da Europa e especialmente na França, onde é conhecido sob a denominação de 'droit de bibliotheque' (Lacerda, 1894, p. 100).

Peregrino pensava na dessacralização do livro, da leitura e, no leitor que, ao colaborar com a aquisição, exigiria os autores indicados, tratamento técnico da obra, análise ou resumo do conteúdo, enfim, disponibilidade e acessibilidade de informações e de objetos gráficos postos em circulação de forma mais 
democrática. Essa prática política parece não ter tido eco entre os membros da congregação. Mas as referências bibliográficas proporcionaram o uso intenso do catálogo, dando novos significados aos processos sociais de circulação da informação (McKenzie, 2018). Com o aumento do número de consultas, Peregrino passou a defender o empréstimo domiciliar, uma forma de estender as horas dedicadas ao estudo e dar sentido à materialidade do texto. Posto em circulação, disponível para consulta e identificação das matérias, conforme informações, lentes e alunos fizeram do catálogo impresso, compilado por Peregrino, fonte de pesquisa do conhecimento registrado. Um instrumento de ordenamento para os livros da Biblioteca da Faculdade de Direito do Recife. - Em 1900 Manoel Cícero Peregrino da Silva foi nomeado Diretor da Biblioteca Nacional, no Rio de Janeiro.

\section{CONCLUSÃo}

Os inventários e os catálogos elaborados na origem do Curso de Sciencias Juridicas e Sociaes foram instrumentos de registro e de difusão bibliográfica que se identificaram e deram significado à materialidade dos livros nas estantes. Para o leitor potencial, em busca de um bom livro, esses verdadeiros acervos ambulantes representavam a ordem do conhecimento e do saber no espaço-tempo. Instrumentos de preservação e de publicidade da produção intelectual, que traziam legitimidade à trajetória histórica dos livros especializados que se identificavam como representação da Biblioteca.

Talvez se possa dizer, hoje, que os catálogos de livros têm algo de solar, que permitem abrigar, representar, desvendar e iluminar caminhos para questões relativas ao pensamento, às autorias, aos títulos, às tipografias, aos formatos, à temporalidade, à apropriação do conhecimento, à administração de uma biblioteca que se impôs no século XIX, em um período politicamente conturbado, do qual derivou um conjunto articulado de experiências com bons livros entre os lentes e os estudantes, repercutindo nos dias atuais. Os catálogos citados reafirmam o percurso socioeconômico e cultural da informação registrada, que exemplificam e cumprem o "dever de memória" da Biblioteca do Curso de Sciencias Jurídicas e Sociaes, atual Faculdade de Direito do Recife da Universidade Federal de Pernambuco.

\section{REFERÊNCIAS}

Araújo, A. V. F. (2018). Sobre a eminência e o eco da bibliografia: nos rastros do método bibliográfico gesneriano e dos fundamentos do campo (Dissertação de mestrado), Universidade de São Paulo, São Paulo. Recuperado de https: //www.teses.usp.br/teses/disponiveis/8/8138/tde-10022009-124405/pt-br.php

Araújo, J. V. (1880). Memória histórico-acadêmica do anno de 1879 lida em sessão da Congregação em 28 de fevereiro de 1880. Recife: Faculdade de Direito do Recife. Recuperado de https://repositorio.ufpe.br/bitstream/123456789/31985/1/366330\%20-\%208888114\%20-\%20Memoria \%20Historica\%20FDR\%20-\%20Jo\%c3\%a3o\%20Vieira\%20de\%20Ara\%c3\%bajo\%20-\%201880.pdf

Bevilaqua, C. (2012). História da Faculdade de Direito do Recife (3a ed.). Recife: Universitária da UFPE.

Blake, A. V. A. S. (1898). Diccionario bibliograhico brasileiro (Vol. 4). Rio de Janeiro: Typographia Nacional.

Brasil. (1827). Lei de 11 de agosto de 1827. Crêa dous Cursos de sciencias juridicas e sociaes, um na cidade de S. Paulo e outro na de Olinda. Recuperado de https://www2.camara.leg.br/legin/fed/lei_sn/1824-1899/lei-38401-11-a gosto-1827-566698-publicacaooriginal-90225-pl.html

Brasil. (1831). Decreto de 7 de novembro de 1831. Aprova provisoriamente os novos estatutos para os cursos de ciências jurídicas e sociais do Império. Recuperado de https://www2.senado.leg.br/bdsf/item/id/227320

Brasil. (1854). Decreto no 1.386, de 28 de abril de 1854. Dá novos Estatutos aos Cursos Jurídicos. Recuperado de

Brasil. (1855). Decreto ${ }^{\circ} 1.568$, de 24 de fevereiro de 1855. Approva o Regulamento complementar dos Estatutos das Faculdades de Direito do Imperio para a execução do $53 .^{\circ}$ do Art. 21 do Decreto no 1.386 de 28 de abril de 1854. 
Recuperado de https://www2.camara.leg.br/legin/fed/decret/1824-1899/decreto-1568-24-fevereiro-1855-55 8483-publicacaooriginal-79790-pe.html

Brasil. (1856). Colleção das leis do Império do Brasil de 1855 (1856, T. 16, 18, Pt. 1-2). Typographia Nacional.

Brasil. (1892). Decreto $\mathrm{n}^{\circ} 1.159$ de 3 de dezembro de 1892. Approva o codigo das disposiçôes communs ás instituições de ensino superior dependentes do Ministerio da Justiça e Negocios Interiores. Recuperado de https://www2.camara.l eg.br/legin/fed/decret/1824-1899/decreto-1159-3-dezembro-1892-520752-publicacaooriginal-1-pe.html

Burke, P. (2003). Uma história social do conhecimento: de Gutenberg a Diderot. Rio de Janeiro: Jorge Zahar.

Calvino, I. (1993). Por que ler os clássicos (N. Moulin, Trad.). São Paulo: Companhia das Letras.

Câmara, P. (1904). Memória histórica da Faculdade de Direito do Recife: ano de 1903. Recife: Imprensa Industrial.

Campos, J. P. de. (1860). Catálogo da Bibliotheca da Faculdade de Direito do Recife, n. 1. Typographia Commercial de Geraldo Henrique de Mira. Recuperado de https://repositorio.ufpe.br/handle/123456789/31360

Chartier, R. (2002). À beira da falésia. a história entre certezas e inquietudes (P. C. Ramos, Trad.). Porto Alegre: UFRGS. Catão, U. F. (1839). [Inventario da Bibliotheca Publ [...] Curso Juridico de [Olin]da. Olinda.

Eco, U. (2010). A vertigem das listas (E. Aguiar, Trad.). Rio de Janeiro: Record.

Faculdade de Direito do Recife. (1834). Officio de 7 de abril de 1834 de Umbelino Ferreira Catão ao Ministro Antonio Pinto Chichorro da Gama. Arquivo.

Faculdade de Direito do Recife. (1835). Officio de 15 de dezembro de 1835. Arquivo.

Farge, A. (1986). Le goût de l'archive. Paris: Le Seuil.

Furetiere, A. (1690). Dictionnaire universel contenant generalement tout les mots François, tant vieux que modernes, et les terms de toutes les sciences et des arts. Chez Arnout \& Reinier Leers. Recuperado de https://gallica.bnf.fr/services/engine/search/sru?operation=searchRetrieve\&version=1.2\&collapsing=disa bled\&rk=42918; $4 \&$ query $=\% 28$ gallica $\% 20$ all $\% 20 \% 22$ diccionaire $\% 20$ furetiere $\% 22 \% 29 \% 20$ and $\% 20$ dc.relatio n\%20all\%20\%22cb32136509c\%22

Gama, M. S. L. (1983). O Carapuceiro (1832-1842) (Vol. 1). Recife: Fundação de Cultura Cidade do Recife.

Kant, E. (1995). Qu'est-ce qu'un livre? París: Quadrige. (J. Benoist, Trad.).

Lacerda, E. B. F. (1894). Memória histórica dos acontecimentos mais notáveis do anno de 1893 apresentado à Congregação da Faculdade de Direito do Recife. Recife: Faculdade de Direito do Recife. Recuperado de https://repositorio.u fpe.br/handle/123456789/32385

Lebvre, L., \& Martin, H.-J. (1992). O aparecimento do livro (F. M. L. Moretto e G. M. Machado, Trad.). São. Paulo: Hucitec.

Malclès, L.-N. (1954). Cours de bibliographie a l'intention des étudiants de l'université et des candidats aux exames de bibliothécaire. Ginebra: Droz.

Mckenzie, D. F. (2018). Bibliografia e a sociologia dos textos. São Paulo: Edusp.

Melot, M. (2006). La sagesse du bibliothécaire. Paris: L'Oeil Neuf.

Mey, E. S. A. (1995). Introdução à catalogação. Brasilia: Briquet de Lemos.

Naudé, G. (1876). Advispour dresser une bibliothèque, présentéa Monseigner le Président de Mesme. Paris: Isidore Liseux.

Ricoeur, P. (2007). A memória, a história, o esquecimento. Campinas, SP: Unicamp.

Rodrigues, L. S. S. (2017). Memória da Faculdade de Direito do Recife. formação do acervo bibliográfico (1828-1835). (Dissertação de mestrado) Universidade Federal de Pernambuco, Recife. Recuperado de https://repositorio.ufpe.br/bitstream/123456789/27814/1/DISSERTA\%C3\%87\%C3\%83O\%20Ligia\%2 0Santos\%20da\%20Silva\%20Rodrigues.pdf

Rouveyre, E. (2000). Dos livros (C. Levys, Trad.). Rio de Janeiro: Casa da Palavra.

Silva, M. C.P. S. (1896). Catálogo geral da Bibliotheca da Faculdade de Direito do Recife. Recife: Empreza D’A Provincia.

Veiga, G. (1981). História das ideias da Faculdade de Direito do Recife, periodo Olinda (Vol. 2). Pernambuco: Universitária da UFPE. 
Veiga, G. (1982). História das ideias da Faculdade de Direito do Recife, periodo Olinda (Vol. 3). Pernambuco: Universitária da UFPE.

Vilela, K. G. F. (2020). Catálogo de Manuel Cícero Peregrino contribuição da bibliografia histórica à organização do conhecimento (Dissertação de mestrado). Universidade Federal de Pernambuco, Recife. Recuperado de https:// repositorio.ufpe.br/handle/123456789/37817 